\title{
WILLINGESS TO CONSUME GENETICALLY MODIFIED FOOD IN CHINESE PERSPECTIVE
}

\author{
Muhammad Asim Nawaz ${ }^{1,2}$, Muhammad Asif ${ }^{3}$, Fahad Asmi ${ }^{4 *}$ and Ali Nawaz \\ ${ }^{1}$ School of Management, University of Science and Technology of China, Hefei, Anhui, 230051, P.R. China; ${ }^{2}$ Lyallpur \\ Business School, Government College University, Faisalabad, Pakistan; ${ }^{3}$ University of Veterinary and Animal \\ Sciences, Lahore, Pakistan; ${ }^{4}$ Department of Science and Technology Communication and Policy, University of Science \\ and Technology of China Hefei, Hefei, 230051, P.R. China; \\ "Corresponding author's email: fasmie@ustc.edu.cn
}

\begin{abstract}
Almost after investing 25 years in research and development, China has reached to the decisional stage to either continue or discontinue or at least reduce the introductory speed of the genetically modified (GM) food production. The current study integrates the Benefit-Risk Analysis (BRA) framework and trust to study the consumer willingness to consume GM food. A structured survey conducted in nine major cities of China among 345 qualified samples analyzed through structural equational modeling-smart partial least square (SEM-Smart PLS). The statistical results lead to the following conclusions: The proposed psychological-persuasive model highlights the "trust in institutions" holds the least explanatory power while communicating about GM food-related risks in society. In the case of mapping perceived benefits, the trust in technology should be improved; as in the overall view of BRA, the perceived benefits hold less explanatory abilities in contrast to perceived risks. In other words, a secure communication strategy can change the public acceptance trend of GM food in China.
\end{abstract}

Keywords: BRA (Benefits-Risks Analysis), institutional trust, trust in technology, revealed information, perceived knowledge, attitude, willingness to consume

\section{INTRODUCTION}

Globally, every nation maintains a different attitude towards GM consumption developed over the spectrum of regional, political, scientific, and psychological dynamics. In the EU, GM food is a political issue, and the consumer holds deleterious intentions regarding consumption (Wunderlich et al., 2015). The US, Argentina, Mexico, Brazil, and India are top GM cultivators with considerable state and public support (Twardowski et al., 2015). Whereas, the fast-developing economies like China exhibit mix response at the general consumer. For example, Statista, (2018) reported 19.6\% support, 33.5\% neutral and 47\% oppose the concept. Despite institutional support, GM perception remains controversial in China. A trust deficit exists between the GM food concept and public perception that $72 \%$ of the Chinese consumer is concerned about the perceived risks associated with the food intake. Higher consumer involvement is consequent of recent food scandals that include the sale of expired and unhygienic meat, pork, beef, adulteration, and food frauds. The nightmare of melamine scandals appeared in 2008 and later in 2010. Such food indignities made food consumption very risky in China and shake consumer trust in commercial food products. The findings of Ma (2013) discussed Chinese consumer attitude towards GM food and found that consumer decision focuses on risk and benefits associated with GM food.
To cope with the trust deficit, the Chinese administration devotedly adopted a scientific approach for risk evaluation (Standaert, 2018). Under MoA (Ministry of Agriculture), the Chinese administration has signed the 'Cartagena Protocol on Biosafety to the Convention on Biological Diversity' in August 2000 to ensure the biosafety (Cui et al., 2018). Moreover, MoA volunteered GM labeling for all GM products to ensure the consumer 'right to know'. Standards observed by the MoA are considered stricter than measures taken in other countries, but still, a trust deficit exists in the GM marketing in China owing to food safety scandals and consumer perception of longer-run health and environmental losses (Cui \& Shoemaker, 2018). Consequently, the consumer is highly concerned with GM technologies and its application (Pechar et al., 2018). The consumer cannot verify the claims about the technology due to a lack of technical knowledge and the complex nature of products. Therefore the possibility of consumer distrust grows manifolds. Consumer depicts distrust in GM food, expecting that GM technology is not trustable, GM labels might contain false information and acquired without adequate procedural requirements, in general consumer might lack the trust in institutions.

The literature provides evidence that Chinese consumer show better intention towards the certified foreign brands, that exhibits consumer distrust in local food manufacturers (Zhang et al., 2016). Moreover, Chinese society as a whole is risk aversive as compared to the modern world (Gong et al., 
2016). The substantial financial and human investment by the Chinese administration heavily depends on the end consumers' response (Kou et al., 2015). Consumers' distrust in the government institutes, regulatory bodies (labeling), technology, and low consumer knowledge might create barriers in the adoption of GM food. Little consideration is given to an in-depth examination of consumer trust in GM food and its influencing factors. In exception to the Zhang et al. (2018) revealing the consumer trust in food safety, product pricing, convenience, trust in regulatory bodies found the trust as an influential factor in creating food consumption willingness. So, the importance of trust increases manifolds for GM food in China.

Whereas on the consumer side, risk evaluation based on the number of losses incurred, and the number of benefits gained (Adenle et al., 2017). In the context of GM Food, BRA (benefit-risk analysis) framework widely adopted to investigate the consumers' willingness to consume (Ayyagari et al., 2011). In general, these two distinct concepts are investigated in separate studies. Interestingly, BRA integrates them into a unified framework. The consumer resents the GM food products due to higher perception of risks (Martin et al., 2017) and in few cases accepted when consumers consider benefits surpass the losses in term of risks (Costa-Font et al., 2008). Based on these facts, this study integrates the trust and BRA framework proposed by the Bredahl (1998). Bredahl (1998) proposed the concept to study the controversial products in light of perceived benefits and associated risk. The current study adopts the Bredahl benefits-risk framework (BRA) to study consumer willingness to consume controversial GM food products. The study will extend the literature on trust in GM food consumption by providing a detailed analysis of variables that can build consumer trust. Moreover, the outcome of the current study will assist the producers, retailers, and marketers in identifying adequate policies and strategies to improve consumers' trust in GM food.

Institutional trust (IT): In GM perspective, institutional trust is the consumer trust in different governmental and industrial institutes that are controlling and monitoring the GM activities. Prior literature suggests that consumer trust in institutes influences the product acceptability (Niu et al., 2018). The trust in institutions is a source of confidence that provides the essential motivation to make a purchase decision. In GM context, institutional trust is consumer trust in procedures, processes, and associated technology checks implemented by the government and industry. The trust can be classified into two broader categories. First situational normality is the belief that the situation is ordinary, and routine based and success is likely. Second structural assurance is the belief that success is dependent on the guarantees, legal coverage, promises, rules, and regulations offered by the institutions (McKnight and Chervany, 2001). For example, regulative trust plays an incremental role in providing confidence to the banking consumer to make investments and trust the banks (Adamson et al., 2003). For GM food, the situation is structural, and the consumer might require institutional guarantees and legal insurances to make a purchase decision. Thus, we propose that:

Hla. Institutional Trust (IT) influences the perceived risk

(PR) of consumers towards GM foods.

H1b. Institutional Trust (IT) influences the perceived benefits $(P B)$ of GM foods.

Trust in technology (TT): Prevailing literature shows that higher consumer trust in technology means higher technology adoption ratio (Chauhan, 2015). In medical science, people react positively to technological advancements, and the adoption rate is high (Todaka et al., 2018). Similar passion observed in the pharmaceutical industry. GM technology implementation in pharmaceutical science is appreciated by consumers. In food, context consumer lacks the appropriate knowledge, skills, and expertise required to evaluate the GM technology (Delshad et al., 2010). In e-commerce, trust in technology is the organizational structural ability to control and monitor the safe use of technology (Ratnasingam et al., 2003). About GM, the consumers are not sure regarding the technology intervention and its adverse impact on naturality, nutrition, and utility of food items (Tsatsakis et al., 2017). Trust in technology might influence the consumers' Willingness to Consume GM food indirectly via perceived risks and benefits, as shown in the proposed hypotheses below:

H2a. Trust in genetic engineering Technology (TT) influence the perceived risk (PR) regarding GM foods.

H2b. Trust in genetic engineering Technology (TT) influence the perceived benefits (PB) of GM foods.

Revealed information (RI): Product Information declared for consumers in term of food labels is an attempt to guide the consumption behavior of individuals (Crespi et al., 2003). The objective to reveal information is to ensure consumer rights to know and choose. Information revealed as nutrition tables, licensing stamps, symbols, text, or allergic alerts (Ragland et al., 2018). This information is placed prominently on product packaging to highlight key characteristics of the food product ( KOU et al., 2015). China is only such country that is offering compulsory GM labeling policy to ensure consumer rights (KOU et al., 2015). Food perceived risks are associated with food frauds in term of wrong claims, e.g., sugar-free, nutritional value, and ingredients. Generally, the consumer is worried about potential health and environmental risks in the short- and long-term period (Shewfelt et al., 2016). study found that labeling influence consumer Willingness to Consume GM food technologies. Huang et al., (2017) concluded that trust in both general and food processing systems impact consumer intentions. Vecchio and Annunziata (2015) found that product labeling enhances consumer benefits perception and decreases the associated risks. Hartmann et al., (2018) studied that labeling can be a potential 
source of consumer confidence in GM technologies. Hartmann et al., (2018) observed that 'free-from' or 'includes' labeling techniques influence the consumer risk perception of food technologies. Based on these arguments, we propose that:

H3a. Revealed Information (RI) influence the perceived risk (PR) of GM foods.

$H 3 b$. Revealed Information (RI) influence the perceived benefits (PB) of GM foods.

Perceived knowledge (PK): Many studies on GM food show that consumer knowledge of edibles increases consumer willingness to consume GM food (Davies, 2017). Although consumption choices are a set of diverse factors such as sensorial, social, cognitive, situational, cultural, and demographic characteristics. Literature provides evidence that mere improvement in consumer knowledge of GM food can enhance willingness to consume (Hairong et al., 2016). Consumer knowledge of products plays an incremental role in consumer behavior, particularly in the case of high involvement products such as GM food products (Davies, 2017). Generally speaking, food products are recognized as low involvement products (Hughner et al., 2007). Whereas, GM food surpasses this threshold level, and consumer involvement increases. Similarly, knowledge is becoming an important indicator to study GM related consumer behavior, and especially when the public interest is high (Bredahl, 2001). Prior research shows that higher the consumer knowledge higher the consumption propensity (Kim et al., 2018). So, consumer perceived knowledge might play a key role in determining consumer consumption willingness towards GM food (Aleksejeva, 2014; Nawaz et al., 2018). Hence, we propose that:

H4a. Perceived Consumer Knowledge (PK) regarding GM foods influence the perceived risk (PR) of GM food consumption.

H4b. Perceived Consumer Knowledge (PK) regarding GM foods influence the perceived benefits $(P B)$ of GM food consumption.

Benefits-risk analysis \& attitude (ATT): Bredahl et al. (1998) studied that the consumer attitude is influenced by the perceived GM food benefits and risks regarding the GM technology use for food production. In general, attitude is positively influenced by the perceived benefits resulting in consumers' willingness to consume (Hairong et al., 2016). Whereas, perceived risks negatively influence the consumer attitude towards the willingness to consume GM food (CostaFont et al., 2008). Perceived benefits regarding the GM food revolves around the nutritional benefits, shelf life, per acre yield and environmental concern in term of reduced energy consumption and chemical usage (Scott et al., 2016). These benefits improve the food supply that consequently reduces the food prices (Huang et al., 2004). The scientists and experts well recognize the perceived benefits of GM food, unlike the perceived risks (Kim et al., 2018). Perceived risks are consumer perception based including side effects, long term health, environment, and social problems (Pusztai et al., 2006). Consumer perceived benefits play a vital role in the acceptance of innovative products. Literature proves that perceived benefits are more influential on consumers' attitude and willingness to consume GM food as compared to the perceived risk of the consumer (Aleksejeva, 2014). In contrast, many studies conclude that consumer perceives more risks than benefits. Amin et al., (2014) observed that perceived benefits and risks are complex and hard to conceptualize separately. Literature affirms the correlations between the perceived benefits and perceived risks (CostaFont et al., 2008). To evaluate these complex relations between perceived benefits and risks, attitude, and consumer willingness to consume GM food, we propose a list of hypotheses as stated below:

H5. Perceived risks (PR) regarding GM foods influence the attitude towards GM foods (GMA).

H6. Perceived benefits (PB) of GM foods influence the consumers' attitude towards GM foods (GMA).

H7. Perceived risks (PR) regarding GM foods influence the consumers' willingness to consume (WC).

H8. Perceived benefits (PB) of GM foods influence the consumers' the consumers' willingness to consume $(W C)$.

H9. The consumers' attitude towards GM foods (GMA) influences the consumers' the consumers' willingness to consume (WC).

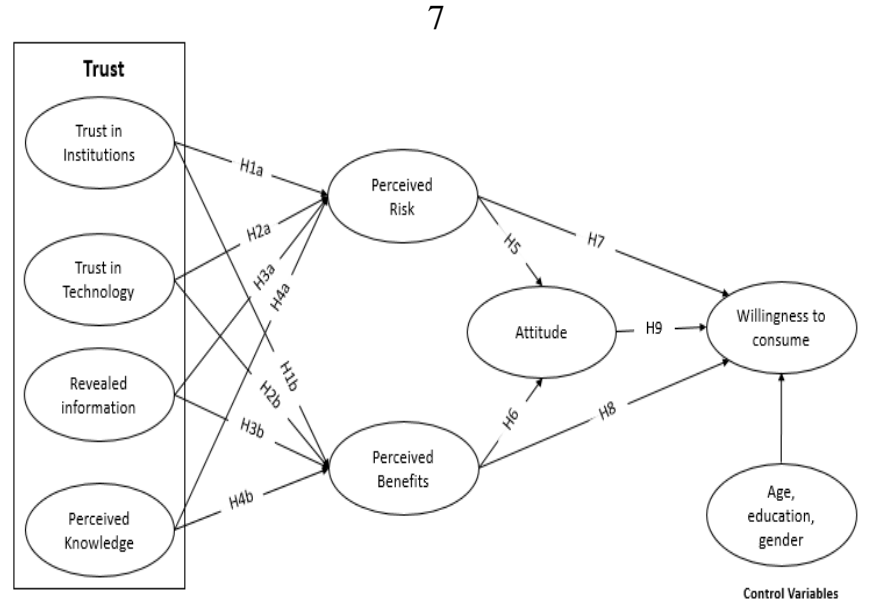

Figure 1. Graphical representation of the 'proposed study framework.

\section{MATERIAL AND METHODS}

To achieve the prime objective of the study, the traditional mode of data collection adopted. The structured instrument of scale adapted with the support of the existing pool of literature to conceptualize consumers' behavior in terms of the persuasive socio-psychological model (Hair et al., 1998). The 
following subsection highlight the instrument development, data collection, and tools to analyze results.

Instruments: To address the content validity concerns, the instrument for each of the construct adapted from the existing literature. Specifically, items for the construct 'trust in institutions' (IT) adapted by Verdurme and Viaene (2003). Items to measure 'trust in technology' adapted by Ratnasingam and Pavlou (2003). Moreover, the instrument to map 'revealed information' and 'perceived knowledge' adapted from Chen (2008), respectively. Bredahl (2001) taken under consideration to define consumers' perceived benefits and risks related to GM food consumption. Furthermore, to understand consumers attitude and willingness to consume GM food, the instrument adapted by Rodríguez-Entrena and Salazar-Ordóñez (2013) in the current study. All constructs related items measured over the continuum of seven Likert scales, whereas ' 1 ' marked as strongly disagree and ' 7 ' as strongly agree as it helps to measure socio-psychological attributers in detail (Hair et al., 1998).

Table1. Demographic description.

\begin{tabular}{llrr}
\hline Measures & Value & Frequency & $\mathbf{( \% )}$ \\
\hline Gender & Male & 186 & 53.91 \\
& Female & 159 & 46.09 \\
& $18-24$ & 94 & 27.29 \\
& $25-30$ & 109 & 31.68 \\
& $31-35$ & 58 & 16.83 \\
Education & H6-40 & 57 & 16.17 \\
& High school graduates & 27 & 7.92 \\
& College graduates & 24 & 7.06 \\
& Bachelors & 155 & 44.92 \\
& Masters & 93 & 26.83 \\
Monthly & PhD & 38 & 11.02 \\
income & 1500-3000 & 35 & 10.17 \\
& 3000-4500 & 175 & 50.72 \\
& $4500-6000$ & 101 & 29.27 \\
& 6000-above & 45 & 13.00 \\
& & 24 & 6.95 \\
\hline
\end{tabular}

Data sampling: The instrument translated into the Chinese language to make it convenient for the target population. As a pilot study, 25 volunteer students invited to engage in the survey process and share their feedback about the refinement of the questionnaire. The revised version of the survey circulated with a cover letter to address the purpose of the study and to assure the ethical concerns of the potential participants. Specifically, the field survey conducted during the fourth quarter of the year 2018, the visitors in the highstreets, and close to fruits and vegetables market requested to participate. Statistically, the simple random sampling technique adopted, were almost 700 individuals requested to participate. However, 465 filled responses received in total. After preliminary examination, and after exclusion of incomplete set of responses, 345 accurate records taken under consideration for the further analysis. The sample size calculated as recommended by Godden (2004). Precisely, it's measured while considering a $5 \%$ margin of error, $95 \%$ confidence interval for the unknown population (recommended sample size $=377$ ). The non-response biasness examined by comparing the results of the initial and lately received responses. No significant difference between both groups assured the current study is free of non-responses biasness.

The demographic characteristics revealed that around $54 \%$ of respondents were male, and $46 \%$ female. Most of the respondent's noted between the age group of 18 to 40 years, and monthly income observed between RMB 1500-5000. Table 1 presents the demographic characteristics in detail.

\section{RESULTS}

The PLS (Partial Least Squares) is well suited for complex models as it has minimum restrictions on measurement scales, sample size, and residual distributions. The study engages the PLS method of SEM (Structural Equation Modeling) to conduct data analysis as PLS can handle complex structures and formative constructs as discussed in the methodology section. PLS-SEM technique that can handle a significant number of variables. SEM postulates two sorts of models: the measurement and structural model. The measurement model defines the constructs of model adapts and assigns observed items to each construct. Whereas, the structural model defines the relationship between these constructs. The SEM application is quite common in psychological, social, and behavioral science research to study the complex models. Moreover, it also helps to examine multivariate data sets in which researchers measure proposed factors. The current study investigates the multiple latent variables by using the SEM technique. A two-stage analysis approach is implemented for data analysis, as discussed below.

Multicollinearity: Multicollinearity continues to be a key concern for social researchers. In PLS-SEM, we can measure the multicollinearity through the variance inflation factor (VIF) which should be equal to or lower than 3.3. In the current study, the value of VIF recorded between the range of 1.372 to 2.679 . Hence, no trace of multicollinearity observed in the current study.

Measurement model: The EFA was performed to examine the internal reliability of each of the construct, the variance extracted from each of the variable, and external validity by inspecting discriminant validity, as shown in the Table 2 below. The internal reliability was measured by 'Cronbach $\alpha$ ' and 'Composite Reliability,' whereas the lower satisfactory limit of 0.70 as recommended by Fornell and Larcker (1981) was observed in the current study. The 'average variance extracted' (AVE) captures the variance extracted by each construct in association with the recorded variance because of measurement error. Statistically, it is advised to be higher than 
0.50 (Hair et al., 2014), which indicates that the current study is valid for further examination. The results derived from EFA concluded the supportive findings as the items loading in case of each construct indicates non-significant factor loadings, as shown in Table 3. Specifically, the factor loadings are recorded between the range of 0.704 to 0.900 .

Table 2. Exploratory factor analysis and reliability analysis.

\begin{tabular}{lllccc}
\hline Variable & Items & Ldng & $\boldsymbol{\alpha}$ & CR & AVE \\
\hline Institutional trust & IT1 & 0.859 & & & \\
& IT2 & 0.796 & 0.774 & 0.863 & 0.678 \\
Trust in & IT3 & 0.814 & & & \\
Technology & TT1 & 0.887 & & & \\
& TT2 & 0.858 & 0.825 & 0.894 & 0.738 \\
Revealed & TT3 & 0.831 & & & \\
Information & RI1 & 0.832 & & & \\
Perceived & RI2 & 0.877 & 0.739 & 0.848 & 0.652 \\
Knowledge & RI3 & 0.704 & & & \\
& PK1 & 0.751 & & & \\
Perceived Risks & PK2 & 0.851 & 0.738 & 0.849 & 0.653 \\
& PK3 & 0.839 & & & \\
& PR1 & 0.839 & & & \\
Perceived Benefits & PR2 & 0.885 & 0.817 & 0.891 & 0.731 \\
& PR3 & 0.839 & & & \\
GM Attitude & PB2 & 0.800 & & & \\
& PB3 & 0.863 & 0.778 & 0.871 & 0.692 \\
& GMA1 & 0.900 & & & \\
Willingness to & GMA2 & 0.895 & 0.866 & 0.918 & 0.788 \\
Consume & GMA3 & 0.868 & & & \\
& WC1 & 0.872 & & & \\
& WC2 & 0.869 & 0.837 & 0.902 & 0.754 \\
& & 0.863 & & & \\
\hline \multirow{4}{*}{ WM } & & & & &
\end{tabular}

In the psychometric analysis, the discriminant validity helped to examine the external validity of each of the construct within the proposed model. Quantitatively, it was measured by computing the square-root of each of the constructs' 'average variance extracted' which supposed to remain above the interconstruct correlation. Thus, the current study also satisfies the criteria of discriminant validity, as shown in Table 3.
Structural model and hypothesis testing: The structural model satisfy all the fitness indices, which can challenge the reliability and validity of the structured model. The research concludes that the hypotheses related to institutional trust (as $\mathrm{H} 1 \mathrm{a}$ ), revealed information (as $\mathrm{H} 3 \mathrm{a}$ ), and perceived knowledge about GM foods (as $\mathrm{H} 4 \mathrm{a}$ ) are not statistically significant to define perceived psychological risks about GM food while defining their attitude and willingness to consume. In other words, the perceived risk demands to revisit more comprehensively i.e. by exploring cultural factors. However, the trust in technology observed to be a critical factor while defining consumer's risk. The study highlights that the strategic use of a trust in technology while communicating the value of GM food to the society can potentially reduce perceived risks related to it (as $\mathrm{H} 2 \mathrm{a}$ noted with $\beta=-0.228$, $\mathrm{p} \leq 0.05)$.

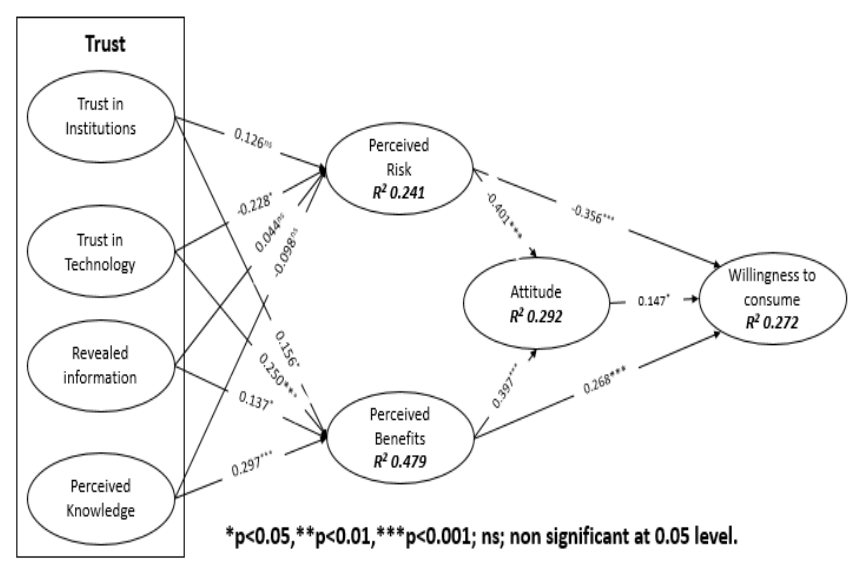

Figure 2. Graphical representation of the 'proposed model' and its path analysis.

Interesting, trust in technology and perceived knowledge recorded as the most influential determinants while explaining consumers' perceived benefits. Statistically, the proposed hypotheses noted as $\mathrm{H} 2 \mathrm{~b}$ with $\beta=-0.250, \mathrm{p} \leq 0.001$, and $\mathrm{H} 4 \mathrm{~b}$ with $\beta=-0.297, \mathrm{p} \leq 0.001$ respectively. Moreover, the study determines that the constructs, namely institutional trust and revealed information are holding comparatively low explanatory power to explain the perceived benefits of GM

Table 3. Correlation, and discriminant validity analysis.

\begin{tabular}{lrrrrrrrr}
\hline & \multicolumn{1}{c}{ IT } & \multicolumn{1}{c}{ TT } & RI & PK & PR & PB & GMA & WC \\
\hline Institutional trust (IT) & $\mathbf{0 . 8 2 3}$ & & & & & & & \\
Trust in technology (TT) & 0.634 & $\mathbf{0 . 8 5 9}$ & & & & & & \\
Revealed information (RI) & 0.410 & 0.563 & $\mathbf{0 . 8 0 8}$ & & & & & \\
Perceived knowledge (PK) & 0.698 & 0.571 & 0.382 & $\mathbf{0 . 8 0 8}$ & & & & \\
Perceived risks (PR) & -0.069 & -0.180 & -0.071 & -0.124 & $\mathbf{0 . 8 5 5}$ & & & \\
Perceived benefits (PB) & 0.577 & 0.595 & 0.455 & 0.600 & 0.083 & $\mathbf{0 . 8 3 2}$ & & \\
GM attitude (GMA) & 0.348 & 0.416 & 0.302 & 0.436 & -0.367 & 0.364 & $\mathbf{0 . 8 8 8}$ & \\
Willingness to consume (WC) & 0.339 & 0.371 & 0.268 & 0.364 & -0.388 & 0.292 & 0.376 & $\mathbf{0 . 8 6 8}$ \\
\hline
\end{tabular}

Note: Boldface numbers are the square root of the AVE of each construct 
food consumption. In other words, hypothesis H1b observed with $\beta=-0.156, p \leq 0.001$, and $\mathrm{H} 3 \mathrm{~b}$ recorded as $\beta=-0.137$, $\mathrm{p} \leq 0.001$. While defining the role of perceived risk, the study highlights that in the presence of perceived higher risks related to GM food consumption reduce the chances of creating favorable consumers' attitude towards GM food (H5: $\beta=-0.401, p \leq 0.001)$ and their willingness to consume it $(\mathrm{H} 7$ : $\beta=-0.356, p \leq 0.001)$. However, the presence of positive perceived benefits of GM food triggers the positive attitude of consumers towards GM food (H6: $\beta=0.397, \mathrm{p} \leq 0.001$ ), and individuals' willingness to consume it (H8: $\beta=-0.268$, $\mathrm{p} \leq 0.001)$. The study further highlights that the attitude of consumers towards GM Food also helps to create a favorable view in terms of consumption willingness (H9: $\beta=0.147$, $\mathrm{p} \leq 0.05$ ). Moreover, none of the proposed control variables holds significant effect over the consumers' willingness to consume GM food in the current study. The tabular representation of all the proposed hypotheses shown in table 4 below.

The current study highlighted the role of trust defining factors as exogenous for defining consumers' perceived risks and benefits. The study concludes that the explanatory power of trust related factors to define perceived benefits is higher as compare to its ability to explain the consumers' perceived risks related to GM food consumption. Statistically, the $\mathrm{R}^{2}$ in the case of perceived risk and benefits are noted as $R^{2}=0.241$ and 0.479 , respectively. Furthermore, it can be stated that the valence view (risks and benefits) is more meaningful while explaining the consumers' attitude, as compared to its ability to define consumers' willingness to consume GM food. Statistically, the attitude and willingness to consume GM food recorded with the $\mathrm{R}^{2}$ value of 0.292 and 0.272 , respectively.

Table 4. Hypotheses testing and path analysis.

\begin{tabular}{llrrl}
\hline Hyp. & Path & Est. & Sign. & Result \\
\hline H1a. & IT $\rightarrow$ PR & 0.126 & 0.103 & Not Supported \\
H1b & IT $\rightarrow$ PB & 0.156 & 0.019 & Supported \\
H2a. & TT $\rightarrow$ PR & -0.228 & 0.011 & Supported \\
H2b. & TT $\rightarrow$ PB & 0.250 & 0.000 & Supported \\
H3a. & RI $\rightarrow$ PR & 0.044 & 0.527 & Not Supported \\
H3b. & RI $\rightarrow$ PB & 0.137 & 0.013 & Supported \\
H4a. & PK $\rightarrow$ PR & -0.098 & 0.269 & Not Supported \\
H4b. & PK $\rightarrow$ PB & 0.297 & 0.000 & Supported \\
H5. & PR $\rightarrow$ GMA & -0.401 & 0.000 & Supported \\
H6. & PB $\rightarrow$ GMA & 0.397 & 0.000 & Supported \\
H7. & PR $\rightarrow$ WC & -0.356 & 0.000 & Supported \\
H8. & PB $\rightarrow$ WC & 0.268 & 0.000 & Supported \\
H9. & GMA $\rightarrow$ WC & 0.147 & 0.014 & Supported \\
\hline Hyp $=$ hypothesis, Est=estimate, Sign=significance
\end{tabular}

Blinding folding: The study adapted the blindfolding procedure to evaluate the relevance of exogenous variables and model performance, with a sample re-use procedure (Chin, 1998). This procedure is the combination of function fitting and cross-validation and examines each construct predictive relevance by computing changes in the criterion estimates $\left(\mathrm{Q}^{2}\right)$. Hair Jr et al. (2017) Describe that $\mathrm{Q}^{2}>0$ shows predictive relevance of the model. The results of StoneGeisser's blindfolding technique $\left(\mathrm{Q}^{2}\right)$ in the current study show that consumers' willingness to consume GM food is $\left(\mathrm{Q}^{2}\right.$ $=0.188$ ) all have satisfactory predictive relevance since their values are above than cut-off level.

\section{DISCUSSION}

The study tests the proposed hypothesis developed from the integrated model that incorporates the trust and BRA to determine the consumer willingness to consume GM food. Whereas, GM consumption willingness is recognized as a complex decision-making process (Costa-Font \& Gil, 2009). The statistical result affirms a set of causal links between different determinants of consumer willingness to consume GM food products. The determinants include trust in technology, institutional trust, revealed information, perceived knowledge, perceived risks, perceived benefits, attitude, and willingness to consume.

The BRA framework in this study along with new findings also support the results of few prior research studies, that assist the formation of vigorous model to analyze the consumer food related attitude and willingness to consume GM food (Bredahl et al., 1998). The study explains how consumer attitude is influenced by perceived benefits and risks under the trust factors. The statistical findings lead to some interesting findings, and the state institutions can play an incremental role in developing consumer choice. The results validate that more significant the trust in institutions higher the perception of the benefits. These findings are indirectly consistent with the related field studies (Pechar et al., 2018). The Chinese consumer exhibit better dependence and trust in state institutions (Cui \& Shoemaker, 2018). This study introduces the "trust in GM technologies," and statistical results reveal that Chinese consumer has a lower level of trust in GM developmental technologies. The findings are unique about GM food. In general, the consumer displays a better response to food technologies (Bearth \& Siegrist, 2016). In the case of GM foods, consumers lack the trust in technology and its implementation (Ishii, 2018). The revealed information contributes positively in shaping consumer benefits perception and make negative input to the perception of the risk; these findings are consistent with the previous findings of (Ragland et al., 2018).

Moreover, the "perceived knowledge" also contributes positively to the benefits and negatively to the perception of the risk that is inline to the previous findings of Vecchione $e t$ al. (2015). The current statistical analysis concludes that: the positive attitude of Chinese consumer regarding GM food increases the consumption willingness, and the perceived risks negatively influence the consumer willingness to 
consume GM food. Moreover, trust factors provide valuable insight into the perceived benefits and risks concerning GM food.

The key findings reaffirm vital explanatory and predictive ability of BRA framework in term of GM acceptance and case of persuasive modeling (Zhang et al., 2018). One of the exciting findings of the current examination is the attitude that can forecast the consumer willingness to consume GM food under the proposed model which is consistent to some of the previous findings (Bredahl et al., 1998). Moreover, in the current integrated approach, consumer attitude is having a statistically significant effect on consumer willingness. Risk perception was found to have a significant influence on consumer willingness to consume. Similarly, statistical results highlight that higher the consumer perception of GM benefits more will be the consumer willingness to consume GM food. The results highlight the critical role of BRA in consumer behavior research, and current study validates BRA strongly.

China is the world's principal producer and import food products and faces constant pressure to ensure the effective and efficient maintenance of food supply. The surveys of $\mathrm{Ma}$ and Huang (2012) found that China should enhance its cultivatable land about $25 \%$ to $30 \%$ to reduce the dependency on imported food items (Hairong et al., 2016). In the current scenario, the consumer perception of GM food is the ultimate factor in GM consumption. The consumer attitude, perceived benefits, and risks regarding the GM food not only influence the commercialization of concept, but at the same time, it determines the future research and development of GM technologies. Examining the factors that develop public concerns in term of GM food are of prime importance for the policymakers. Is the consumer willingness to consume GM food affected by the perceived risks and benefits? It is the ultimate question to be answered by the policymakers (Lusk et al., 2005). In the recent past, the Chinese government has invested in the research, development and promotion of novel food technologies e.g., in 2008, China launched a multibillion nationwide GM breeding program (Hairong et al., 2016). In promotional campaigns, the scientific popularization knowledge and technology features should be given appropriate intention. The improved GM knowledge will help the consumer to develop an inclusive and unbiased view of the present importance of GM, it's history, safety, environmental benefits and GM risks to make a better decision regarding GM technologies. These factors will improve consumer awareness of the perceived benefits of technology use and will influence the consumer behavioral response to GM food in a positive manner. Eventually, that will influence the commercialization of GM food items and related technologies (Rodríguez-Entrena et al., 2013).

Existing literature verifies the role of trust in a general way. In this study, trust affects consumer attitude and consumption willingness through many paths. Such as institutional trust- perceived benefits-attitude-willingness. In the present case, trust plays a vital role to enhance consumer willingness regarding GM food, and this is a critical factor for policymakers to pounder. The current results extend the role of institutional trust in consumer willingness. The general consumer cannot afford the cost necessary to understand GM technology and product-related knowledge. Moreover, they lack the sources to gain practical knowledge of the emerging concept. Many survey studies have highlighted the scare knowledge of Chinese consumers regarding GM technologies (Huang et al., 2006). So, the policymakers must enhance the communication of technology-related aspects and its related processes along with communicating knowledge to the public.

Moreover, the current findings validate the role of perceived benefits of GM food. If more benefits are communicated to the consumers as compared to the risks, consumer attitude can be altered that will influence the final decision of consumer willingness to consume (Lusk et al., 2005; Costa-Font and Gil, 2009). Despite the numerous development and application of GM technologies around the world, Chinese consumer perception remains negative. Understanding the consumer preferences of technology and its implementation can provide further insight into the policymakers and food industry to meet the changing consumer requirements (CostaFont et al., 2008). So, we recommend that the manufacturer and food processing industry must reevaluate the risks and benefits of GM technologies and its implementation to enhance public acceptance before going for the commercialization (Amin et al., 2013). GM studies that systematically investigate the empirical and theoretical explanation of the consumer willingness to consume GM food are limited (Costa-Font et al., 2008). The present study contributes to the literature by integrating the theoretical framework and empirical evidence on the process leading to the consumers' willingness to consume GM food. This paper adds to the existing body of the literature that explanations the determinants of consumer willingness to consume GM. The approach adopted in this study can be further engaged by the researchers to investigate the consumer food attitude and purchase intentions towards GM technologies and food items. Although the current research initiative comprised the most comprehensive view of 'Trust' over BRA in case of GMF acceptance and persuasive modeling; however, it also comprises a few limitations and leads for future research. Firstly, Urbanization in China has drastically changed the demographical situation, whereas almost $70 \%$ of the population lives in an urban area. The data collected in the current research only emphasized the urban areas of the cities, and view that is more comprehensive can be analyzed in the future studies. The 'role of media', 'social network analysis in terms of its tie strength' and 'framing strategy for GM Food acceptance' can be observed in the future studies, which can lead to further interesting findings in the case of GM Food 
acceptance in China. The economic concerns, and further bifurcation of risks (i.e., psychological, and social risks) holds the potential to leads to further findings. Moreover, the holistic view by involving technocrats, media personals, and other mythological approaches are required which can provide further interesting findings for academicians, researchers, scientists and institutions while introducing safer and more advance version of GM foods and technology in the society.

Conclusion: The growing concerns of consumers suggest that consumption willingness of GM food is becoming increasingly controversial; the data collected through this study suggest that a high number of consumers lacks trust in GM food technology which holds less explanatory power while defining consumers" perceived risks related to GM food. However, trust as exogenous in the case of consumers' perceived benefits of GM food defines the consumer's view with comprehensive manner. Further, the potential GM consumer exhibit trust in state institutions. This difference of belief in technology and state institutions open up a window of opportunity for Chinese administration to further support the GM food concept and educate the general public about the sophisticated technologies adapted for GM research and development. The study further highlights the vital role of revealed information and perceived knowledge, which demands holistic communication strategy for better understanding of socio-scientific issues (i.e. GM food acceptance in society). The consumer looks for adequate labels on the product. The concept of labeling is somewhat controversial, but consumer demands disclosure and considers it a positive step towards gaining consumer confidence. Moreover, the study extends the GM literature as it found that the perception of risks and benefits influences the consumer attitude towards the GM consumption willingness. The authorities should focus on communicating more benefits to the food consumers and answer the consumer mysteries and misconceptions in a scientific way to improve the consumer willingness to consume. Finally, the results of this research point to the significant role of trust in determining GM based risks and benefits that affect the consumer attitude and willingness to consume GM food. Continued research in this direction will assist in widening the scope to recognize the diverse range of consumer concerns regarding the GM food, as well as increasing the understanding of values and believes of consumers, and also the factors that determine the consumer decision making related to food.

\section{REFERENCES}

Adamson, I., K. M. Chan and D. Handford. 2003. Relationship marketing: Customer commitment and trust as a strategy for the smaller Hong Kong corporate banking sector. Int. J. Bank Mark. 21:347-358.
Adenle, A. A., E. J. Morris and D. J. Murphy. 2017. Genetically modified organisms in developing countries : risk analysis and governance. Cambridge University Press.

Aleksejeva, I. 2014. EU Experts' Attitude Towards Use of GMO in Food and Feed and Other Industries. Procedia Soc. Behav. Sci. 110:494-501.

Amin, L., M. A. K. Azad, N. A. Ahmad Azlan and F. Zulkifli. 2014. Factors influencing stakeholders' attitudes toward cross-kingdom gene transfer in rice. New Genet. Soc. 33:370-399.

Ayyagari, R., V. Grover and R. Purvis. 2011. Technostress: technological antecedents and implications. MIS Q. 35:831-858.

Bearth, A and M. Siegrist. 2016. Are risk or benefit perceptions more important for public acceptance of innovative food technologies: A meta-analysis. Trends Food Sci. Technol. 49:14-23.

Bredahl, L., K. G. Grunert and L. J. Frewer. 1998. Consumer Attitudes and Decision-Making With Regard to Genetically Engineered Food Products - A Review of the Literature and a Presentation of Models for Future Research. J. Consum. Policy. 21:251-277.

Bredahl, L. 2001. Determinants of Consumer Attitudes and Purchase Intentions With Regard to Genetically Modified Foods - Results of a Cross-National Survey. J. Consum. Policy. 24:23-61.

Chauhan, S. 2015. Acceptance of mobile money by poor citizens of India: integrating trust into the technology acceptance model. info. 17:58-68.

Chen, M. F. 2008. Consumer trust in food safety - A multidisciplinary approach and empirical evidence from Taiwan. Risk Anal. 28:1553-1569.

Chin, W. W. 1998. The partial least squares approach to structural equation modeling. Mod. Methods Bus. 295:

Costa-Font, M., J. M. Gil and W. B. Traill. 2008. Consumer acceptance, valuation of and attitudes towards genetically modified food: Review and implications for food policy. Food Policy. 33:99-111.

Costa-Font, M. and J. M. Gil. 2009. Structural equation modelling of consumer acceptance of genetically modified (GM) food in the Mediterranean Europe: A cross country study. Food Qual. Prefer. 20:399-409.

Crespi, J. M. and S. Marette. 2003. 'Does Contain' vs. 'Does Not Contain': Does it matter which GMO label is used? Eur. J. Law Econ. 16:327-344.

Davies, A. 2017. Consumer Products and Consumer Behavior. Consum. Percept. Prod. Risks Benefits. Springer International Publishing, Cham, pp. 319-343.

Delshad, A. B., L. Raymond, V. Sawicki and D. T. Wegener. 2010. Public attitudes toward political and technological options for biofuels. Energy Policy. 38:3414-3425.

Fornell, C. and D. Larcker. 1981. Evaluating structural equation models with unobservable variables and 
measurement error. J. Mark. Res. 18:39-50.

Godden, B. 2004. Sample Size Formulas. www.williamgodden.com/.

Gong, Y., K. Baylis, R. Kozak and G. Bull. 2016. Farmers' risk preferences and pesticide use decisions: evidence from field experiments in China. Agric. Econ. 47:411421.

Hair, J., W. Black, B. Babin, R. Anderson and R. Tatham. 1998. Multivariate data analysis 5th edn. Prentice Hall, Upper Saddle River, NJ.

Hairong, Y., C. Yiyuan and H. B. Ku. 2016. China's soybean crisis: the logic of modernization and its discontents. J. Peasant Stud. 43:373-395.

Hartmann, C., S. Hieke, C. Taper and M. Siegrist. 2018. European consumer healthiness evaluation of 'Freefrom' labelled food products. Food Qual. Prefer. 68:377388.

Hirschberg, C., A. Rajko, T. Schumacher and M. Wrulich. 2016. The changing market for food delivery. Mckinsey Rep. New York, New York, NY, USA, Beijing nong ye da xue xue bao bian ji shi

Huang, H. W., S. J. Wu, J. K. Lu, Y. T. Shyu and C. Y. Wang. 2017. Current status and future trends of high-pressure processing in food industry. Food Control. 72:1-8.

Huang, J., R. Hu, H. van Meijl and F. van Tongeren. 2004. Biotechnology boosts to crop productivity in China: trade and welfare implications. J. Dev. Econ. 75:27-54.

Huang, J., H. Qiu, J. Bai and C. Pray. 2006. Awareness, acceptance of and willingness to buy genetically modified foods in Urban China. Appetite. 46:144-151.

Hughner, R. S., P. McDonagh, A. Prothero, C. J. Shultz and J. Stanton. 2007. Who are organic food consumers? A compilation and review of why people purchase organic food. J. Consum. Behav. 6:94-110.

Ishii, T. 2018. Crop Gene-Editing: Should We Bypass or Apply Existing GMO Policy? Trends Plant Sci. 23:947950.

Jr, J. H., M. Sarstedt, C. Ringle, S. Gudergan. 2017. Advanced issues in partial least squares structural equation modeling.

Kim, N. H., J. Y. Hwang, H. G. Lee, M. K. Song, Y. S. Kang and M. S. Rhee. 2018. Strategic approaches to communicating with food consumers about genetically modified food. Food Control. 92:523-531.

Kou, J. Ping, Q. Ling Tang and X. Fa Zhang. 2015. Agricultural GMO safety administration in China. J. Integr. Agric. 14:2157-2165.

Li, Y., X. Wang, X. Lin and M. Hajli. 2016. Seeking and sharing health information on social media: A net valence model and cross-cultural comparison. Technol. Forecast. Soc. Change.

Ma, X. and P. Huang. 2012. How Many World's Agricultural Resources China Use Nowadays. Issues Agric. Econ. 12:4-10.
McKnight, D. H. and N. L. Chervany. 2001. What Trust Means in E-Commerce Customer Relationships: An Interdisciplinary Conceptual Typology. Int. J. Electron. Commer. 6:35-59.

Niu, G. and G. Zhao. 2018. Identity and trust in government: A comparison of locals and migrants in urban China. Cities. 83:54-60.

Pavlou, P. A., H. Liang and Y. Xue. 2007. Understanding and Mitigating Uncertainty in Online Exchange Relationships: A Principal-Agent Perspective. MIS Q. 31:105.

Pechar, E., T. Bernauer and F. Mayer. 2018. Beyond Political Ideology: The Impact of Attitudes Towards Government and Corporations on Trust in Science. Sci. Commun. 40:291-313.

Pusztai, A. and S. Bardocz. 2006. Chapter 17 GMO in animal nutrition: potential benefits and risks. Biol. Grow. Anim. 4:513-540.

Ragland, R. E., J. L. Mansfield and D. A. Savaiano. 2018. A Universal Label for GMOs. Nutr. Today. 53:40-46.

Ratnasingam, P. and P. A. Pavlou. 2003. Technology Trust in Internet-Based Interorganizational Electronic Commerce. J. Electron. Commer. Organ. 1:17-41.

Rodríguez-Entrena, M., M. Salazar-Ordóñez. 2013. Influence of scientific-technical literacy on consumers' behavioural intentions regarding new food. Appetite. 60:193-202.

Scott, S. E., Y. Inbar and P. Rozin. 2016. Evidence for Absolute Moral Opposition to Genetically Modified Food in the United States. Perspect. Psychol. Sci. 11:315324.

Shewfelt, R. L. and R. L. Shewfelt. 2016. How Does Food Processing Change the Nutritional Value of Foods? Def. Process. Food. Springer International Publishing, Cham, pp. 107-123.

Standaert, M. 2018. China struggling with consumer skepticism in push to introduce GMO corn | Genetic Literacy Project.

Statista. 2018. Genetically Modified Crops - Statistics; Facts | Statista .

Todaka, K., J. Kishimoto, M. Ikeda, K. Ikeda, H. Yamamoto. 2018. Impact of Risk-Benefit Perception and Trust on Medical Technology Acceptance in Relation to Drug and Device Lag. Ther. Innov. Regul. Sci. 52:629-640.

Tsatsakis, A. M., M. Amjad, V. A. Tutelyan, K. S. Golokhvast, O. ioanna Kalantzi, D. Hwa, S. Jo, M. D. Coleman, N. Tyshko, S. Hwan and G. Chung. 2017. Impact on environment, ecosystem, diversity and health from culturing and using GMOs as feed and food. Food Chem. Toxicol. 107:108-121.

Twardowski, T. and A. Małyska. 2015. Uninformed and disinformed society and the GMO market. Trends Biotechnol. 33:1-3.

Vecchio, R., A. Annunziata. 2015. Willingness-to-pay for 
sustainability-labelled chocolate: an experimental auction approach. J. Clean. Prod. 86:335-342.

Vecchione, M., C. Feldman and S. Wunderlich. 2015. Consumer knowledge and attitudes about genetically modified food products and labelling policy. Int. J. Food Sci. Nutr. 66:329-335.

Verdurme, A. and J. Viaene. 2003. Consumer Attitudes Towards GM Food. J. Int. Food Agribus. Mark. 13:7798.

Wunderlich, S. and K. A. Gatto. 2015. Consumer Perception of Genetically Modified Organisms and Sources of Information. Int. J. Adv. Nutr.842-851.
Zhang, L., Y. Xu, P. Oosterveer and A. P. J. Mol. 2016a. Consumer trust in different food provisioning schemes: Evidence from Beijing, China. J. Clean. Prod. 134:269279.

Zhang, M., C. Chen, W. Hu, L. Chen and J. Zhan. 2016 b. Influence of source credibility on consumer acceptance of genetically modified foods in China. Sustain. 8:1-16.

Zhang, Y., L. Jing, Q. Bai, W. Shao, Y. Feng, S. Yin and M. Zhang. 2018. Application of an integrated framework to examine Chinese consumers' purchase intention toward genetically modified food. Food Qual. Prefer. 65:118128. 